\title{
Flunarizine, a Calcium Channel Antagonist, Is Partially Prophylactically Neuroprotective in Hypoxic-Ischemic Encephalopathy in the Fetal Sheep
}

\author{
ALISTAIR J. GUNN, CHRISTOPHER E. WILLIAMS, E. CARINA MALLARD, WILLIAM K. M. TAN, \\ AND PETER D. GLUCKMAN
}

The Research Centre for Developmental Medicine and Biology. University of Auckland, Auckland, New' Zealand

\begin{abstract}
Calcium antagonist therapy has been reported to reduce neuronal death after hypoxia-ischemia; however, its potential use in prenatal hypoxic-ischemic events has received little attention. We examined the effect of pretreatment with flunarizine in chronically instrumented late gestation fetal sheep subjected to $30 \mathrm{~min}$ of cerebral ischemia. Eight fetuses were given $0.11 \mathrm{mmol}$ (45 mg) of flunarizine over $2 \mathrm{~h}$ preischemia (high dose), 10 were given $0.07 \mathrm{mmol}(30 \mathrm{mg}$ ) over $3 \mathrm{~h}$ preischemia (low dose), 17 were given nothing (ischemia controls), and 5 received neither the ischemic insult nor any treatment (sham controls). The fetal electrocorticogram was monitored for $3 \mathrm{~d}$ postinsult. Histologic outcome was quantified after $72 \mathrm{~h}$. Low-dose, but not high-dose, flunarizine therapy was associated with an overall reduction in cerebral damage $(p<0.01$ ), a greater final electrocorticogram intensity, and a reduction in the incidence of seizures $(p<0.02)$ compared with ischemia controls. High-dose, but not lowdose, flunarizine was associated with a significant acute mortality and a decrease in fetal blood pressure $(p<0.05)$ at the time of occlusion, although there was no effect on the initial hypertensive response to occlusion. These observations suggest that flunarizine is partially neuroprotective when given before severe global ischemia in utero, but that its hypotensive effects make it unsuitable for prophylactic administration in utero. (Pediatr Res 35: 657-663, 1994)
\end{abstract}

\section{Abbreviations}

BP, arterial blood pressure

$\mathrm{CBF}$, cerebral blood flow

ECoG, electrocorticogram

FHR, fetal heart rate

NGF, nerve growth factor

MANCOVA, multivariate analysis of covariance

Calcium entry secondary to ischemic depolarization and excitatory neurotransmitter release is one mechanism leading to neuronal death after a hypoxic-ischemic insult (1). There is increasing experimental evidence that prophylactic treatment with calcium channel blockers can reduce the degree of cerebral

Received April 19, 1993: accepted January 25, 1994.

Correspondence: Alistair J. Gunn. Department of Paediatrics, University of Auckland, Private Bag. Auckland. New Zealand.

Supported by grants from the Medical Research Council of New Zealand, the Neurological Foundation, and the Auckland Medical Research Foundation. damage from such insults in adult $(2,3)$ and immature $(2,4-6)$ animals.

Perinatal hypoxic-ischemic encephalopathy affects approximately six of 1000 term infants (7) and occurs primarily prepartum or intrapartum (8). Although the safety of antepartum treatment of compromised fetuses is unresolved (9), prophylactic use of neuroprotective agents may be possible in at-risk infants (6). Flunarizine is a lipid-soluble calcium channel antagonist known to pass the blood-brain and placental barriers and to inhibit depolarization-induced uptake of calcium (2). We have previously shown flunarizine to be dramatically protective in infant rats when given before $2 \mathrm{~h}$ of hypoxia-ischemia (5). We have recently described an experimental approach to global cerebral ischemia in utero that produces severe delayed postischemic epileptiform activity with parasagittal cortical infarction (10, 11). This pattern is similar to that seen in some asphyxiated term infants, supporting the hypothesis that parasagittal hypoxicischemic encephalopathy is of ischemic origin, resulting from a period of impaired cerebral perfusion $(8,12)$. This preparation, which allows a reproducible insult to be delivered to a stable animal, without systemic compromise, is very suitable for testing possible therapeutic interventions in hypoxic-ischemic encephalopathy. Ultimately of course, promising interventions also need to be tested using a more pathophysiologic, and more variable, asphyxial approach (13). In this study, we tested the effect of flunarizine when given immediately before $30 \mathrm{~min}$ of cerebral ischemia in the fetal sheep.

\section{MATERIALS AND METHODS}

Forty eight Romney/Suffolk fetal sheep from 116 to $126 \mathrm{~d}$ of gestation were instrumented under halothane anesthesia $(2 \%)$ as previously described (10). The electrophysiologic and histologic outcome in 14 of the fetuses (nine ischemia controls and five sham controls) have previously been reported $(10,11)$. Briefly, catheters were inserted into the brachial arteries and vein and amniotic cavity. Two pairs of shielded stainless steel electrodes were placed over the parietal dura, at $10 \mathrm{~mm}$ lateral to the bregma, and $5 \mathrm{~mm}$ and $15 \mathrm{~mm}$ anterior to the bregma. The vertebral-occipital anastomoses between the carotid arteries and vertebral arteries were ligated bilaterally to eliminate vertebral blood supply to the brain. Inflatable occluder cuffs were placed around both carotid arteries. The fetus was then returned to the uterus, the leads and catheters externalized to the maternal flank, and the uterine and abdominal walls sutured closed. As part of a pilot study, four of the fetuses were instrumented as above, but without the carotid artery cuffs or ligation of the anastomoses.

After the operation, the ewes were housed in metabolic cages at constant temperature $\left(20^{\circ} \mathrm{C}\right)$ and humidity $(50 \%)$ with free access to hay and water supplemented by sheep nuts and alfalfa. 
Antibiotics (penicillin, $1 \mathrm{~g}$; gentamicin, $80 \mathrm{mg}$ ) were administered daily for $4 \mathrm{~d}$ starting at surgery. All experiments were started 72 to $96 \mathrm{~h}$ after surgery.

Recordings. The fetal parietal ECoG from 1 to $30 \mathrm{~Hz}$ was recorded and its intensity (power) spectrum analyzed in real time as previously reported $(10,14)$ for $4 \mathrm{~h}$ before any intervention and for $72 \mathrm{~h}$ postinsult; the ECoG was also recorded on an analog chart running at $5 \mathrm{~mm} / \mathrm{min}$. Fetal BP, corrected for amniotic fluid pressure, was recorded using the Real-Time Data Acquisition System [developed by P.S. Dale (15)] and averaged at 1-min intervals for $2 \mathrm{~h}$ before any intervention and for $1 \mathrm{~h}$ after the occlusion. Before experimentation, arterial blood samples were analyzed for blood gases, $\mathrm{pH}$, oxygen saturation, $\mathrm{Hb}$, and lactate, and only fetuses with normal arterial blood gases for our laboratory $(\mathrm{pH}>7.3$ and arterial oxygen tension $>2.27 \mathrm{kPa}$ ) were used.

Experimental procedures. Flunarizine (Janssen Pharmaceutica, Beerse, Belgium) was dissolved in $1 \mathrm{~mL}$ of Tween 80 (polysorbate 80 ) per $150 \mathrm{mg}$ of flunarizine, and then made up to $10 \mathrm{~mL}$ with saline. It was administered systemically as a slow infusion through the brachial vein. As part of a pilot study, four fetuses received infusions of $0.22 \mathrm{mmol}(90 \mathrm{mg})$ of flunarizine over $1 \mathrm{~h}$ (approximately $10 \mathrm{mg} / \mathrm{kg}$ of fetal weight). This was associated with a significant decrease in BP of $15.6 \pm 7 \%$ at the end of the infusion but not at the time that half the infusion had been given $(-2 \pm 4 \%)$. A similar infusion of the diluent only, 2 $d$ later, had no effect on fetal BP $(-0.5 \pm 2 \%)$. We therefore chose to begin our study with a dose of $0.11 \mathrm{mmol}(45 \mathrm{mg})$ of flunarizine over $2 \mathrm{~h}$. Because of a number of complications, including hypotension and unexplained death, described in the results, the dose and infusion rate were subsequently reduced to $0.07 \mathrm{mmol}(30 \mathrm{mg})$ over $3 \mathrm{~h}$. These two dose groups were considered separately.

Cerebral ischemia was induced by inflating the carotid cuffs with saline for $30 \mathrm{~min}$, and successful occlusion was confirmed by the rapid $(<30 \mathrm{~s})$ suppression of the ECoG to isoelectricity. Because we have found that a number of cuffs burst immediately after inflation, we prospectively chose to use animals in whom this occurred as sham controls for changes in ECoG intensity over the subsequent $3 \mathrm{~d}$ and for histologic outcome (10).

The experimental fetuses were $125 \pm 3 \mathrm{~d}$ old $(119-131 \mathrm{~d})$ at the time of the insult, and their postmortem weights $(3.2 \pm 0.5$ $\mathrm{kg}$ ) were normal by the standards of our laboratory; these parameters were not significantly different between the treatment groups. On the day of experimentation, animals were assigned to either control or flunarizine-treatment groups, as shown in Table 1. Eight fetuses were given $0.11 \mathrm{mmol}(45 \mathrm{mg})$ of flunarizine over $2 \mathrm{~h}$, starting $1.5 \mathrm{~h}$ preischemia (high-dose group); 10 fetuses were given $0.07 \mathrm{mmol}(30 \mathrm{mg})$ over $3 \mathrm{~h}$, starting $2.5 \mathrm{~h}$ preischemia (low-dose group); and 17 were ischemia controls. The infusion was timed to finish at the end of carotid occlusion. In addition, there were five sham controls (no treatment), and four flunarizine-treated fetuses whose cuffs failed (Table 1). No sham-insulted animal, treated or untreated, developed neuronal loss or any loss or perturbation of ECoG intensity after $72 \mathrm{~h}$. These experiments were approved by the Animal Ethics Committee of the University of Auckland.

Histology. Surviving fetuses were killed $72 \mathrm{~h}$ postischemia by

Table 1. Numbers of fetuses entered into each treatment group*

\begin{tabular}{lccl}
\hline & $\begin{array}{c}\text { No } \\
\text { treatment }\end{array}$ & $\begin{array}{c}\text { High } \\
\text { dose }\end{array}$ & $\begin{array}{l}\text { Low } \\
\text { dose }\end{array}$ \\
\hline Ischemia & 17 & 8 & 10 \\
No ischemia (sham controls) & 5 & $(1) \dagger$ & $(3) \dagger$
\end{tabular}

* High dose $=0.11 \mathrm{mmol}(45 \mathrm{mg})$ of flunarizine during $2 \mathrm{~h}$; low dose $=0.07 \mathrm{mmol}(30 \mathrm{mg})$ of flunarizine during $3 \mathrm{~h}$. See Materials and Methods for a description of the groups.

† The drug-treated sham groups have not been included in the analysis because of the small sample sizes. overdose of pentobarbital, and histologic sections of the brains were obtained as previously described (10); no histology was performed on fetuses that died during or shortly after the insult. Briefly, the brain was perfused through the common carotid arteries with saline followed by $10 \%$ formalin, embedded in paraffin, coronally subserially sectioned to $8 \mu \mathrm{M}$, and then stained with thionine-acid fuchsin (16). Each section was examined with light microscopy by two assessors, one of whom was blind to the study. Each region was scored in a number of preassigned areas for the proportion of neurons with ischemic cell change, with acidophilic (red) cytoplasm and contracted nuclei, or with just a thin rim of red cytoplasm with pyknotic nuclei. Such cells were assessed as dead and all others were considered viable. The damage scores were as follows: $0=$ no dead neurons, $5=>0-10 \%, 30=>10-50 \%, 70=>50-90 \%$, $95=90-<100 \%$, and $100=100 \%$ dead neurons $(10,11)$. Each score corresponds with the midpoint of its range. The score for each region consisted of the average of the scores for all spots assessed within that region. The proportion of areas within the parasagittal cortex showing infarction, with evidence of death of glia as well as neurons (16), was also recorded.

Analysis. ECoG intensity (power) was log transformed [dB, $10 \cdot \log$ (intensity)], because this transformation gives a better approximation of the normal distribution (17). The intensity was then normalized with respect to the 4-h control period; thus, all measurements are expressed as a ratio of the baseline period. Time-series analysis of the ECoG data was based on data smoothed with a digital Blackman low-pass filter to minimize short-term $(<10$-min) fluctuations. The final ECoG intensity was calculated on the final 4-h period, from 68 to $72 \mathrm{~h}$; the preseizure intensity was based on a 1 -h period immediately before the start of seizures, as determined from the analog trace. The suppression time of the ECoG was defined as the time postinsult that the ECoG was more than $5 \mathrm{~dB}$ below the baseline intensity, whereas the start of postinsult seizure activity was defined as the $10 \%$ point of increase to the peak. We have previously shown that this abrupt increase in intensity, with a marked decrease in median frequency, corresponds with tonic-clonic activity recorded by diaphragmatic electromyogram (10). The median frequency of the ECoG was calculated from saved spectra at four periods: the 4-h control, during the infusion, from 5 to $30 \mathrm{~h}$, and from 68 to $72 \mathrm{~h}$. Because of technical failure of the ECoG recording, two ischemia controls and one low-dose animal were rejected from the analysis of the postinsult ECoG results. For technical reasons, cardiovascular recordings were not available for seven ischemia controls and three low-dose fetuses.

Comparisons of histology, ECoG, biochemical, and cardiovascular parameters were made by multivariate analysis of variance. Cerebral region and time were treated as repeated measures, to allow for repeated sampling. For comparisons over time, baseline levels were used as a covariate (MANCOVA). Where significant differences were found, post hoc comparisons of the means were made using the Neuman-Keuls test and adjusted using the baseline levels as the covariate, whereas changes relative to baseline were tested with the Wilcoxon paired comparisons test. Fisher's Exact test was used to test proportions.

\section{RESULTS}

Ischemia controls. After 30 min of bilateral carotid occlusion, with complete suppression of the ECoG during ischemia, the ECoG remained suppressed to less than $5 \mathrm{~dB}$ for $6.9 \pm 2.6 \mathrm{~h}$ (Fig. 1). Continuous, intense, low-frequency epileptiform activity appeared after $7.6 \pm 3.2 \mathrm{~h}$ and peaked after $10.0 \pm 5.3 \mathrm{~h}$; the ECoG intensity for the $1-\mathrm{h}$ period immediately preceding the onset of seizures was very suppressed (Table 2). The epileptiform activity progressively resolved over the following $48 \mathrm{~h}$, and by 72 $\mathrm{h}$ postinsult the ECoG intensity was dramatically reduced compared with baseline intensity (Table 2 ). The median frequency 

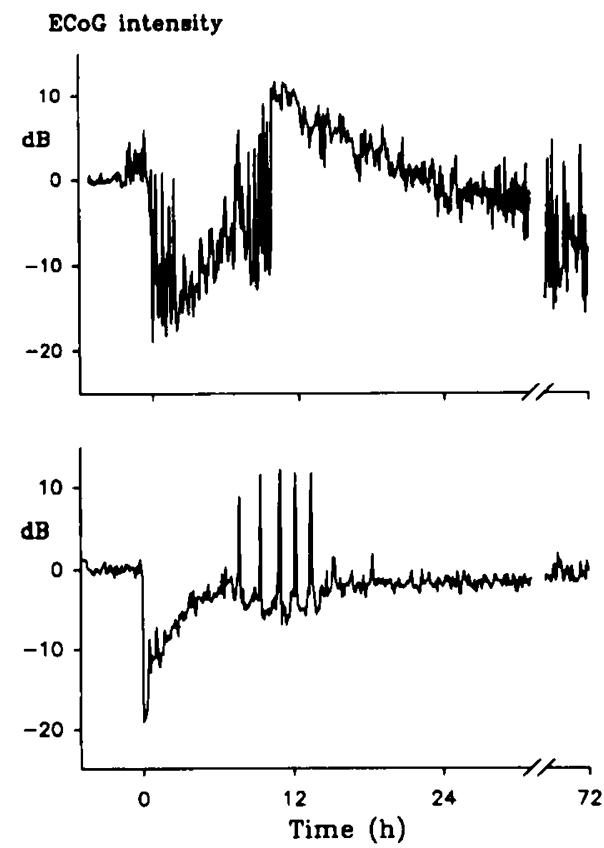

Fig. 1. Time course of changes in ECoG intensity in a representative ischemia control fetal sheep (top panel) and a flunarizine-treated fetus (bottom panel) after $30 \mathrm{~min}$ of cerebral ischemia. Time is shown as hours post-carotid artery occlusion. Flunarizine was given as an infusion of $0.07 \mathrm{mmol}(30 \mathrm{mg})$ starting $2.5 \mathrm{~h}$ before the insult and terminated at the end of the insult. The ischemia control fetus showed marked suppression of the ECoG for about $9 \mathrm{~h}$ after the insult, then developed continuous intense low-frequency epileptiform activity. In the flunarizine-treated animal (bottom), the recovery in ECoG intensity was greater and more rapid before the onset of isolated episodes of intense epileptiform activity.

of the ECoG decreased postinsult and remained low at $72 \mathrm{~h}$ (Table 3).

A mild metabolic acidosis developed during carotid artery occlusion $(p<0.05$, Table 4$)$, accompanied by a trivial increase in oxygen content that was not different between the treatment groups. The arterial carbon dioxide tension showed no significant changes in any group $(6.88 \pm 0.56 \mathrm{kPa})$. Changes in fetal cardiovascular parameters are shown in Table 5 . Carotid artery occlusion caused a dramatic increase in fetal BP $(p<0.01)$ that peaked at $6.2 \pm 2.0 \mathrm{~min}$ and resolved rapidly after release. A progressive tachycardia during occlusion also was seen.

Histologic analysis of these 17 ischemia control fetuses (Fig. 2) showed that there was severe neuronal loss in a watershed pattern, with predominant damage in the parasagittal cortex, with laminar necrosis, and in the hippocampus. In $72 \pm 16 \%$ of parasagittal areas there was evidence of infarction.

High dose. Three high-dose but no control (sham or ischemia) or low-dose animals developed an abrupt, severe bradycardia and hypotension and died ( $p<0.02$, Fisher Exact test) during
( $n=2$, before ischemia) or shortly after the end of flunarizine infusion ( $n=1$, during ischemia). In surviving animals $(n=5)$, there was a similar overall pattern of changes in ECoG activity in the ischemia controls (Table 2). Although the ECoG suppression time was shorter $(4.2 \pm 2.2 \mathrm{~h}, p<0.05)$, the peak intensity occurred at a similar time $(10.5 \pm 6.9 \mathrm{~h})$ and was of similar magnitude. The preseizure and final ECoG intensities were not significantly different from those of ischemia controls (Table 2). During the last $30 \mathrm{~min}$ of flunarizine infusion before occlusion, there was a slight shift to lower frequencies (Table 3 ) but no alteration of the pattern of postinsult changes compared with ischemia controls.

There was an overall decrease in BP during flunarizine infusion in the surviving fetuses compared with ischemia controls $(p<$ 0.02 , MANCOVA), with a decrease of $9.2 \pm 4.4 \%$ compared with baseline ( $p<0.02$, Wilcoxon Matched Pairs test) in the final $30 \mathrm{~min}$ before occlusion and a reduced increase in BP during occlusion. There was no overall alteration in the changes in fetal heart rate or the metabolic factors compared with ischemia controls (Tables 4 and 5).

Although the histologic scores were not significantly different from those of ischemia controls (Fig. 2), only $49 \pm 34 \%$ of parasagittal areas showed infarction $(p<0.02$ versus controls).

Low dose. The 10 low-dose fetuses showed a significantly shorter suppression time $(2.8 \pm 2 \mathrm{~h}, p<0.01)$, although the time of onset of peak activity occurred at a similar time (11.6 \pm 6.2 h), with a nonsignificant trend toward reduced peak intensity. Both the preseizure and final intensities of the ECoG were improved compared with those in the ischemia controls $(p<$ 0.005 , Table 2 ), although they were still significantly lower than in sham controls. Although five fetuses developed delayed continuous seizure activity as seen in the ischemia controls, the remaining five showed a modified pattern (Fig. 1) of greater preseizure recovery of the ECoG, followed by a small number of discrete episodes of intense epileptiform activity $(p<0.02$, Fisher's Exact test).

The median frequency of the ECoG showed a significantly better recovery compared with that of ischemia controls $(p<$ 0.05 , Table 3 , MANCOVA), with a higher median frequency by $72 \mathrm{~h}$. There was a small shift to lower frequencies during flunarizine infusion compared with baseline $(p<0.05)$.

Significant hypotension did not occur during infusion $(p=$ 0.3 ), but the pattern of changes in BP was significantly changed $(p<0.01)$, with a blunted increase during and immediately after occlusion (Table 5). The pattern of changes in fetal heart rate and the metabolic factors was not significantly altered compared with that in ischemia controls (Tables 4 and 5).

Neuronal loss was reduced in treated animals $(p<0.001$, multivariate analysis of variance). The improvement was most dramatic in the cortex and striatum $(p<0.001)$, with a lesser degree of protection in the hippocampus $(p<0.05)$ and no significant difference in the CA3 subfield (Fig. 2). Parasagittal infarction was correspondingly reduced to $20 \pm 20 \%$ of the areas assessed $(p<0.001)$.

Stepwise multiple linear regression analysis of ECoG changes

Table 2. Changes in fetal ECoG intensity*

\begin{tabular}{lcccccc}
\hline \multicolumn{1}{c}{ Group $(n)$} & Infusion & Occlude & Preseizure & $5-30 \mathrm{~h}$ & Peak & Final \\
\hline Ischemia control (15) & $0.02 \pm 0.5$ & $-19.6 \pm 2.7 \dagger \ddagger$ & $-8.8 \pm 2.8 \dagger$ & $-0.4 \pm 3.7$ & $6.1 \pm 4.7 \dagger \ddagger$ & $-8.8 \pm 5.4+\ddagger$ \\
Sham control (5) & $0.06 \pm 0.4$ & $0.03 \pm 0.8$ & N $/ \mathrm{A}$ & $0.52 \pm 0.3$ & $0.65 \pm 0.4$ & $2.4 \pm 1.5 \dagger$ \\
High dose (5) & $-0.5 \pm 1.5$ & $-20.6 \pm 1.4 \dagger \ddagger$ & $-6.5 \pm 3.6 \dagger$ & $1.6 \pm 3.3$ & $6.0 \pm 5.7 \dagger \ddagger$ & $-6.6 \pm 4.5 \dagger \ddagger$ \\
Low dose (9) & $-0.01 \pm 1.2$ & $-19.9 \pm 1.5 \dagger \ddagger$ & $-4.8 \pm 2.3+\S$ & $-1.2 \pm 2.4$ & $2.4 \pm 4.7 \dagger$ & $-4.1 \pm 2.6 \dagger \ddagger \S$ \\
\hline
\end{tabular}

* ECoG intensity is expressed in $\mathrm{dB}$ (mean $\pm \mathrm{SD}$ ) relative to the baseline period. Infusion = last 60 min of flunarizine infusion before ischemia; Occlude $=$ ECoG intensity at the end of occlusion; Preseizure $=1 \mathrm{~h}$ period immediately before the onset of epileptiform activity postinsult; Peak $=$ peak intensity after release of occlusion; and Final $=68$ to 72 postocclusion. N/A, not applicable. The low-dose but not the high-dose group showed a different pattern of changes in ECOG intensity compared with ischemia controls $(p<0.01$, multivariate analysis of variance).

$\dagger p<0.05$ compared with values preocclusion.

$\ddagger p<0.05$ vs sham controls.

$\S p<0.05$ vs ischemia controls. 
Table 3. Changes in fetal ECoG median frequency $(\mathrm{Hz})^{*}$

\begin{tabular}{lcccc}
\hline \multicolumn{1}{c}{ Group $(n)$} & Baseline & Infusion & $5-30 \mathrm{~h}$ & Final \\
\hline $\begin{array}{l}\text { Ischemia control } \\
\quad 10.8 \pm 1.9\end{array}$ & $10.5 \pm 1.8$ & $5.7 \pm 1.8 \dagger \ddagger$ & $6.6 \pm 2.1 \dagger \ddagger$ \\
Sham control (5) & $10.5 \pm 1.2$ & $10.5 \pm 1.5$ & $10.4 \pm 1.1 \S$ & $10.2 \pm 1.2 \S$ \\
High dose (5) & $10.6 \pm 0.9$ & $9.8 \pm 1.1 \dagger$ & $5.4 \pm 1.1 \dagger \ddagger$ & $6.5 \pm 2.2 \dagger \ddagger$ \\
Low dose (9) & $10.3 \pm 1.5$ & $9.3 \pm 2.1 \dagger$ & $6.4 \pm 1.4 \dagger \ddagger$ & $8.2 \pm 2.1 \ddagger \S$ \\
\hline
\end{tabular}

* Infusion = last $60 \mathrm{~min}$ of i.v. infusion of flunarizine before occlusion; $5-30 \mathrm{~h}=25-\mathrm{h}$ period postinsult; and Final $=68$ to $72 \mathrm{~h}$ postinsult. $\mathrm{ECoG}$ intensity is expressed in $\mathrm{db}$ (mean $\pm \mathrm{SD}$ ) relative to the baseline period. Compared with baseline and with the sham controls, all three experimental groups showed a marked decrease in median frequency between 5 and $30 \mathrm{~h}$ postinsult, corresponding with low-frequency spike wave activity at that time. In both the ischemia controls and the highdose group, the median frequency remained low even after resolution of this phase, at $72 \mathrm{~h}$, but the low-dose group showed significant improvement $(p<0.05$, MANCOVA).

$\dagger p<0.05$ compared with the baseline period.

$\ddagger p<0.05$ vs sham controls

$\S p<0.05 v s$ ischemia controls.

in experimental fetuses against damage in the underlying parasagittal cortex suggested that both the duration of suppression postinsult $(r=0.45)$ and the final ECoG intensity $(r=-0.74$, Fig. 3) were correlated with damage in the underlying cortex $\left(r^{2}=0.9, p<0.001\right)$. Although the peak (seizure) intensity was not significantly associated with neuronal loss $(r=-0.17)$, the difference between peak intensity and ECoG intensity before the onset of seizures did show a weak correlation $(r=0.46, p<$ 0.05 ). The fetuses with intermittent rather than continuous postinsult seizure activity also showed a markedly lower proportion of the parasagittal cortex with infarction $(6.7 \pm 9.7$ versus $66.7 \pm 21.3 \%, p<0.001)$. The final ECoG intensity and the preseizure intensity were closely intercorrelated $(r=0.82, p<$ $0.001)$.

\section{DISCUSSION}

This is the first large-animal study confirming that an appropriate dose of a calcium antagonist can protect the fetal brain from ischemic injury. Fetuses treated with a low dose showed a more rapid and complete recovery of ECoG activity after ischemia. These electrophysiologic improvements were associated with a dramatic reduction in damage in the underlying cortex. High-dose therapy, which was associated with a consistent mild hypotension and significant mortality, did not significantly ameliorate neuronal loss, although the extent of infarction was reduced.

One of the few clinical situations in which prophylactic therapy for hypoxic-ischemic encephalopathy might be a viable strategy is the treatment of the fetus at risk for asphyxia (18). Despite this, only limited information has been available to date. In the fetal rat subjected to umbilical cord occlusion, prophylactic therapy with nimodipine, given to the mother, reduced postnatal histochemical derangement and behavioral impairment (6). Previous studies in adult $(2,3)$ and immature $(4,5)$ animals suggest that pretreatment with $10-40 \mathrm{mg}$ of flunarizine per $\mathrm{kg}$ is associated with reduced neuronal damage after ischemia or hypoxiaischemia.

In contrast, rescue therapy, although a more clinically viable strategy, seems to be much less effective. Clinical studies of treatment with calcium antagonists after cardiac arrest (19) or perinatal asphyxia (20) have found no clear benefit. Indeed, Levene et al. (20) reported that an incremental infusion of nicardipine, starting within $12 \mathrm{~h}$ of severe asphyxia, was associated with severe hypotension in two of four cases.

These data are consistent with the experimental evidence. Although Thiringer et al. (21) reported enhanced recovery of somatosensory evoked potentials after treatment with $3 \mathrm{mg}$ of lidoflazine $2 \mathrm{~h}$ after $10-15 \mathrm{~min}$ of cardiac arrest in newborn sheep, the cocktail of compounds given and the excessively short follow-up limit interpretation. Nimodipine did not improve CBF or ECoG recovery after $5 \mathrm{~min}$ of total asphyxia in the beagle pup (22), and flunarizine did not reduce cerebral damage in the infant rat after severe hypoxia-ischemia (23). In adult species, although an early study reported global protection with flunarizine treatment (24), subsequent studies have found either no improvement (3) or reduced damage only in the hippocampus $(1,3,25,26)$, which is the region where delayed, excessive calcium entry has been most clearly documented $(1,27)$.

In this study, we found greatest improvement in the cortex, with the least protection from damage in the hippocampus. This difference compared with the preferential improvement in the hippocampus found in many adult studies (3) might be related to a number of factors, including the immaturity of the fetal brain, the stable thermal environment in utero, and the prophylactic approach used. In addition, rats developing overt seizures are usually excluded from adult studies of ischemia (28), which may well alter the pathogenesis of damage (29).

The slight increase in arterial lactate levels during and immediately after ischemia is almost certainly caused by cerebral anaerobic metabolism during ischemia, which may only have partially resolved by $30 \mathrm{~min}$ postischemia (30). Because uteroplacental lactate transport has a limited rate, the extra lactate produced would not be expected to be fully cleared by that time (31).

The primary mechanism of any neuroprotective effect has not been established. Flunarizine is a lipophilic calcium channel antagonist binding to the dihydropyridine binding site (2). Its

Table 4. Changes in fetal metabolic status during carotid artery occlusion*

\begin{tabular}{lrrrrr}
\hline & Baseline & $0 \mathrm{~min}$ & $30 \mathrm{~min}$ & $60 \mathrm{~min}$ & $72 \mathrm{~h}$ \\
\hline $\mathrm{pH}$ & & & & & \\
$\quad$ Ischemia controls & $7.37 \pm 0.02$ & $7.34 \pm 0.03$ & $7.32 \pm 0.03 \dagger$ & $7.33 \pm 0.03$ & $7.34 \pm 0.03$ \\
$\quad$ High dose & $7.36 \pm 0.02$ & $7.33 \pm 0.04$ & $7.30 \pm 0.05 \dagger$ & $7.33 \pm 0.04$ & $7.37 \pm 0.04$ \\
$\quad$ Low dose & $7.35 \pm 0.02$ & $7.35 \pm 0.02$ & $7.33 \pm 0.02 \dagger$ & $7.35 \pm 0.02$ & $7.36 \pm 0.03$ \\
$\mathrm{CaO}_{2}(\mathrm{mM})$ & & & & \\
$\quad$ Ischemia controls & $3.6 \pm 0.94$ & $3.58 \pm 1.03$ & $3.78 \pm 0.79 \dagger$ & $3.45 \pm 0.60$ & $3.45 \pm 1.11$ \\
High dose & $3.42 \pm 0.41$ & $3.24 \pm 0.37$ & $3.39 \pm 0.91 \dagger$ & $3.38 \pm 0.78$ & $2.48 \pm 0.22$ \\
$\quad$ Low dose & $4.35 \pm 0.47$ & $3.99 \pm 1.02$ & $4.60 \pm 0.20 \dagger$ & $4.29 \pm 0.18$ & $3.72 \pm 1.41$ \\
Lactate (mM) & & & & \\
$\quad$ Ischemia controls & $1.78 \pm 1.03$ & $2.48 \pm 0.72$ & $2.98 \pm 1.02 \dagger$ & $3.74 \pm 1.27 \dagger$ & \\
High dose & $2.3 \pm 0.54$ & $2.8 \pm 0.76$ & $3.75 \pm 0.44 \dagger$ & $4.28 \pm 0.85 \dagger$ & \\
Low dose & $1.68 \pm 0.43$ & $1.92 \pm 0.34$ & $3.48 \pm 0.70 \dagger$ & $3.06 \pm 0.37 \dagger$ &
\end{tabular}

* Values are mean $\pm \mathrm{SD}$. $\mathrm{CaO}_{2}$, arterial oxygen content. Time is from start of occlusion; thus, 60 min represents 30 min after release of occlusion. Lactate levels were not measured at the time of death.

$\dagger p<0.05$ compared with preocclusion values. There was no significant difference between flunarizine-treated and ischemia control animals for any metabolic parameter. 
Table 5. Changes in fetal cardiovascular parameters during carotid artery occlusion*

\begin{tabular}{|c|c|c|c|c|c|}
\hline & Baseline & Infusion & Peak & Occlusion & Recovery \\
\hline \multicolumn{6}{|l|}{$\mathrm{BP}(\mathrm{kPa})$} \\
\hline Ischemia controls & $6.35 \pm 0.67$ & $6.39 \pm 0.63$ & $9.75 \pm 1.03 \dagger$ & $8.65 \pm 1.12$ & $7.12 \pm 0.85 \dagger$ \\
\hline High dose & $6.05 \pm 0.55$ & $5.51 \pm 0.65 \dagger \ddagger$ & $8.03 \pm 0.91+\ddagger$ & $6.99 \pm 0.55 t \ddagger$ & $5.76 \pm 1.04$ \\
\hline Low dose & $5.97 \pm 0.81$ & $5.95 \pm 0.75$ & $7.99 \pm 1.55 \dagger \ddagger$ & $7.04 \pm 1.27 \dagger$ & $5.89 \pm 1.01$ \\
\hline \multicolumn{6}{|c|}{ Fetal heart rate (beats/min) } \\
\hline Ischemia controls & $168 \pm 15$ & $171 \pm 16$ & $185 \pm 17 \dagger$ & $199 \pm 22 \dagger$ & $178 \pm 20$ \\
\hline High dose & $182 \pm 16$ & $179 \pm 17$ & $211 \pm 48 \dagger$ & $227 \pm 58 \dagger$ & $195 \pm 40$ \\
\hline Low dose & $187 \pm 27$ & $183 \pm 29$ & $196 \pm 24 \dagger$ & $215 \pm 35 \dagger$ & $195 \pm 17$ \\
\hline
\end{tabular}

* Baseline $=2$-h period before any intervention; Infusion = final $30 \mathrm{~min}$ before occlusion; Peak = peak BP or fetal heart rate during occlusion; Occlusion $=$ mean level during occlusion; and Recovery $=$ mean BP for 60 min after occlusion. Values are mean \pm SD. The high-dose group $(n=$ $5)$ showed a significant overall reduction in BP compared with the ischemia controls $(n=10)(p=0.02$, MANCOVA). The low-dose group $(n=7)$ did not show a significant overall reduction but showed a significant alteration in the pattern of BP changes $(p<0.01)$ with a blunted response to carotid occlusion. An increase in heart rate developed during occlusion that was not significantly different between the groups (MANCOVA).

$\dagger p<0.05$ compared with preocclusion values.

$\ddagger p<0.05$ vs ischemia controls.

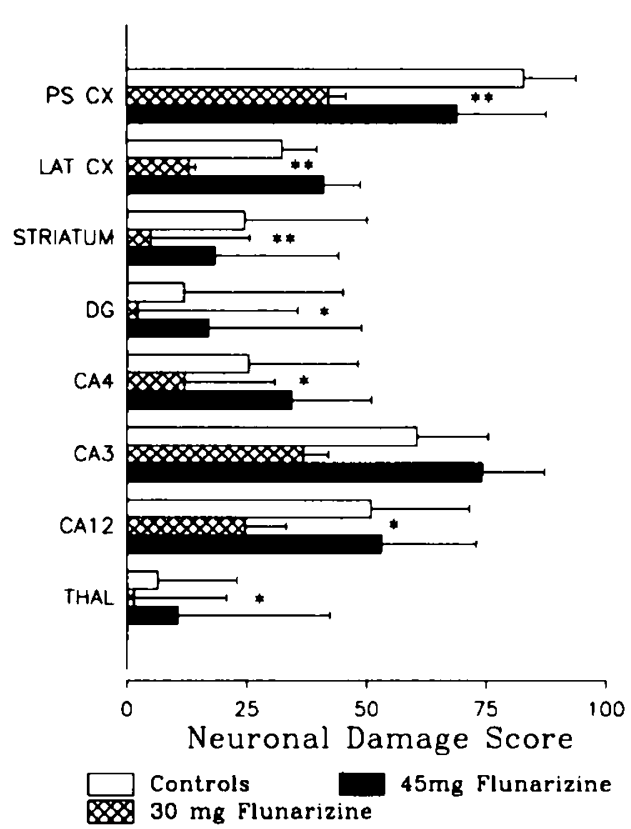

Fig. 2. Neuronal damage scores (mean \pm SD) for different cerebral regions comparing ischemia controls $(n=17)$ and fetal sheep treated with flunarizine (high dose, $n=5$; low dose, $n=10$ ) immediately before 30 min of hypoxia-ischemia. PS CX, Parasagittal parietal cortex; $L A T$ $C X$, lateral (temporal) cortex; $D G, C A I 2, C A 3$, and $C A 4$ are regions of the hippocampus. Low-dose flunarizine therapy was associated with a significant global reduction in neuronal loss $(p<0.001)$. Sham control fetuses showed no neuronal loss.

effects are believed to be mediated by blocking the slow L-type voltage-gated calcium channel (24), although it is also reported to be a potent antagonist of the transient T-type channels in the hypothalamus (32). Flunarizine has been shown to inhibit depolarization-induced uptake of calcium into rat synaptosomes in vitro (33) and to delay the decrease in extracellular calcium in the hypoxic rat brain (34). This may be a critical intervention, inasmuch as high intracellular calcium levels, because of depolarization secondary to energy failure and to enhanced excitatory neurotransmitter activity, are associated with neuronal dysfunction and death $(1,35)$. Reducing the influx by blocking the voltage-gated channels may reduce calcium-mediated metabolic derangements such as degradation of structural lipids or the cytochrome oxidase system $(1,6)$.

Other possible mechanisms have been suggested. Similar to other calcium antagonists, flunarizine is an anticonvulsant (2) that has been reported to increase levels of the inhibitory purine adenosine by affecting reuptake and to alter neurotransmitter

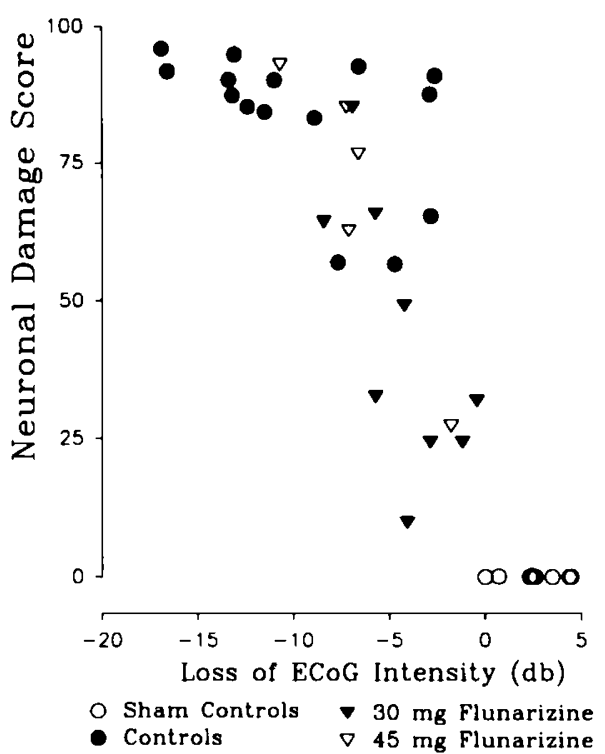

Fig. 3. Relationship between loss of ECoG intensity relative to the baseline intensity, $72 \mathrm{~h}$ postinsult, and neuronal damage scores in the underlying parasagittal cortex. The sham controls show no loss or small increases in baseline intensity $(p<0.05 v s$ baseline, $p<0.001$ compared with the experimental groups), and the ischemia controls show profound loss of ECoG intensity with severe neuronal loss, whereas the low-dose group shows intermediate values. The low-dose but not the high-dose group values are significantly different from those of the ischemia controls for both parameters $(p<0.01)$

release in tissue slices (36), presumably by modulating the effects of voltage-dependent channels during depolarization (37). Seizures may aggravate cerebral damage induced by asphyxia (1), and in the fetal sheep are associated with a secondary increase in intracellular edema, suggesting that this period is associated with delayed neuronal death (29). Although we found in this study that fewer treated fetuses showed continuous high-intensity seizure activity and that this reduction in seizure activity was associated with a very large reduction in the amount of cortical infarction, the significantly earlier and better recovery of ECOG activity before the onset of seizures suggests that neuronal protection during the insult and possibly immediately afterward was more important than reduced secondary damage.

The other major possible mechanism of action is improved CBF due to selective cerebral vasodilation (2) during or after the insult. Although flunarizine has been reported to improve CBF during or after hypoxia-ischemia (2), alterations in CBF induced by the calcium channel antagonists have not been consistently related to improvement in neurologic damage (3). Both no 
improvement in outcome despite increased CBF (3) and reduced damage despite no alteration in CBF during global ischemia (38) have been reported. Because it has been suggested that loss of autoregulation means CBF is essentially pressure passive during and immediately after hypoxia-ischemia in the newborn (39), the hypotension that occurred in the high-dose group in this study may have compromised recirculation after release of the carotid cuffs and thus may explain the reduction in protective effect seen at this dose. Nevertheless, the low-dose group showed dramatic protection despite an impaired BP response to carotid occlusion.

Other interactions might also influence the differing effects at different doses. Flunarizine is reported to prevent the secondary degeneration of NGF-dependent cholinergic basal forebrain neurons seen after axonal transection (40). The mechanism is unclear, but may again be related to effects on calcium entry. In peripheral sensory neurons studied in vitro, NGF acts reciprocally with neuronal activity to improve survival by stabilizing calcium homeostasis (41). In hippocampal pyramidal cells in vitro, IGF-I and IGF-II, fibroblast growth factor, and NGF are associated with a dose-related reduction in calcium entry and improvement in survival during hypoglycemia or exposure to excess glutamate $(42,43)$. NGF release is affected by interactions with other growth factors such as the cytokine transforming growth factor- $\beta$ (44). Transforming growth factor- $\beta$ has recently been reported to dramatically reduce damage after severe hypoxia-ischemia in the rat at intermediate doses but not at either high or low doses (45). These data suggest that complex interactions between endogenous (or exogenous) neurotrophic factors, voltage-dependent calcium channels, and neurotransmitters are likely to be involved in determining neuronal survival in hypoxicischemic encephalopathy.

Calcium antagonists have been used to reduce uterine activity but have been suggested to compromise fetal circulation (9). Jensen and Klossek (46) report that an i.v. bolus of $1 \mathrm{mg}$ of flunarizine per $\mathrm{kg} 60 \mathrm{~min}$ before $2 \mathrm{~min}$ of total fetal asphyxia in the fetal sheep caused only a transient period of hypotension, which is consistent with our data. Although there was an increase in CBF to some parts of the brain, there was a trend toward reduced placental blood flow. Despite flunarizine's known selectivity for the cerebral rather than the systemic circulation (2), we found that larger doses were associated with a mild but consistent hypotension. These doses cannot be considered to be excessive a priori, because in view of its very rapid transplacental passage in the rat (2) and the sheep (unpublished data), the dose administered will have rapidly equilibrated with the ewe.

The significant acute mortality seen in three otherwise healthy fetuses found in this study must give rise to caution. We also found that flunarizine was toxic when given to sick fetuses (18); although they would very likely have died anyway, collapse only occurred after infusion was started. Because death in both groups was associated with an abrupt onset of hypotension and bradycardia, this suggests that the toxic effect was primarily cardiac. Inasmuch as many fetuses at risk for asphyxia will have been compromised by acute or chronic placental insufficiency, the very fetuses whom we wish to treat may be least able to tolerate therapy, as shown by the severe hypotension seen after asphyxia with therapy with the water-soluble calcium antagonist nicardipine discussed above (20).

In summary, this study supports the suggestion that treatment with flunarizine is partially neuroprotective to the fetus when given before a severe hypoxic-ischemic insult. Low-dose therapy was associated with much more rapid recovery after ischemia, suggesting that it reduces the primary injury rather than secondary damage. The propensity to cause hypotension particularly at the higher doses is such that use in high-risk deliveries would be inappropriate at present. Additional studies of flunarizine or similar agents, particularly using asphyxial insults in utero, are needed to further elucidate the mechanisms of neuronal injury (18).

\section{REFERENCES}

1. Siesjö BK, Bengtsson A 1989 Calcium fluxes, calcium antagonists, and calciumrelated pathology in brain ischemia, hypoglycemia, and spreading depression: a unifying hypothesis. J Cereb Blood Flow Metab 9:127-140

2. Todd PA, Benfield P 1989 Flunarizine. A reappraisal of its pharmacological properties and therapeutic use in neurological disorders. Drugs 38:481-499

3. Sakabe T 1989 Calcium entry blockers in cerebral resuscitation. Magnesium $8: 238-252$

4. Silverstein FS, Buchanan K, Hudson C, Johnston MV 1986 Flunarizine limits hypoxia-ischemia induced morphologic injury in immature rat brain. Stroke
$17: 477-482$

5. Gunn AJ, Mydlar T, Bennet L, Faull R, Gorter S, Cook CJ, Johnston BM, Gluckman PD 1989 The neuroprotective actions of a calcium channel antagonist, flunarizine, in the infant rat. Pediatr Res 25:573-576

6. Shen Y, Isaacson RL, Smotherman WP 1991 The behavioral and anatomical effects of prenatal umbilical cord clamping in the rat and their alteration by the prior administration of nimodipine. Restor Neurol Neurosci 3:11-22

7. Levene MI, Kornberg J, Williams THC 1985 The incidence and severity of post asphyxial encephalopathy in full-term infants. Early Hum Dev 11:21-

8. Hill A 1991 Current concepts of hypoxic-ischemic cerebral injury in the term newborn. Pediatr Neurol 7:317-325

9. Ducsay CA, Thompson JS, Wu AT, Novy MJ 1987 Effects of calcium entry blocker (nicardipine) tocolysis in rhesus macaques: fetal plasma concentrations and cardiorespiratory changes. Am J Obstet Gynecol 157:1482-1487

10. Williams CE, Gunn AJ, Gluckman PD, Synek B 1990 Delayed seizures occurring with hypoxic-ischemic encephalopathy in the fetal sheep. Pediatr Res 27:561-565

11. Williams CE, Gunn AJ, Mallard EC, Gluckman PD 1992 Outcome after ischemia in the developing sheep brain: an electroencephalographic and histological study. Ann Neurol 31:14-21

12. Volpe JJ, Herscovitch P, Perlman JM, Kreusser K, Raichle ME 1985 Positron emission tomography in the asphyxiated term newborn: parasagittal impairment of cerebral blood flow. Ann Neurol 17:287-296

13. Gunn AJ, Parer JT, Mallard EC, Williams CE, Gluckman PD 1992 Cerebral histological and electrophysiological changes after asphyxia in fetal sheep. Pediatr Res 31:486-491

14. Williams CE, Gluckman PD 1990 Real-time spectral intensity analysis of the EEG on a microcomputer. J Neurosci Methods 32:9-13

15. Dale PS, Ducsay CA, Gilbert RD, Koos BJ, Longo LD, Power GG 1989 A microcomputer program for real time data acquisition in the perinatal physiology laboratory. J Dev Physiol 11:185-188

16. Smith M, Auer RN, Siesjö BK 1984 The density and distribution of ischemic brain injury in the rat following $2-10 \mathrm{~min}$ of forebrain ischemia. Acta Neuropathol 64:319-332

17. Gasser T, Bacher P, Mocks J 1982 Transformations towards the normal distribution of broad band spectral parameters of the EEG. Electroencephalogr Clin Neurophysiol 53:119-124

18. Gunn AJ, Williams CE, Bennet L, Cook CJ, Gluckman PD 1988 Perinatal cerebral asphyxia: pharmacological intervention. Fetal Ther 3:98-107

19. Brain Resuscitation Clinical Trial II Study Group 1991 A randomized clinical study of a calcium-entry blocker (lidoflazine) in the treatment of comatose survivors of cardiac arrest. N Engl J Med 324:1225-1231

20. Levene MI, Gibson NA, Fenton AC, Papathoma E, Barnett D 1990 The use of a calcium channel blocker, nicardipine, for severely asphyxiated newborn infants. Dev Med Child Neurol 32:567-574

21. Thiringer K, Hrbek A, Karlsson K, Rosen K, Kjellmer I 1987 Postasphyxial cerebral survival in newborn sheep after treatment with oxygen free radical scavengers and a calcium antagonist. Pediatr Res 22:62-66

22. Ment LR, Stewart WB, Duncan CC, Pitt BR 1987 Beagle pup model of perinatal asphyxia: nimodipine studies. Stroke 18:599-605

23. Gunn AJ, Gluckman PD 1991 Flunarizine, a calcium channel antagonist, is not neuroprotective when given after hypoxia-ischemia in the infant rat. Dev Pharmacol Ther 17:205-209

24. Van Reempts J, Haseldonckx M, Van Deuren B, Wouters L, Borgers M 1986 Structural damage of the ischemic brain: involvement of calcium and effects of postischemic treatment with calcium entry blockers. Drug Dev Res 8:387395

25. Lu HR, Van Reempts J, Haseldonckx M, Borgers M, Janssen PA 1990 Cerebroprotective effects of flunarizine in an experimental rat model of cardiac arrest. Am J Emerg Med 8:1-6

26. Kumar K, Krause G, Koestner A, Hoehner T, White BC 1987 Effect of flunarizine on global brain ischemia in the dog: a quantitative morphologic assessment. Exp Neurol 97:115-127

27. Jorgensen MB, Johansen FF, Diemer NH 1987 Removal of the entorhinal cortex protects hippocampal CA-1 neurons from ischemic damage. Acta Neuropathol (Berl) 73:189-194

28. Pulsinelli W, Brierley JB 1979 A new model of bilateral hemispheric ischemia in the unanesthetized rat. Stroke 10:267-272

29. Williams CE, Gunn AJ, Gluckman PD 1991 Time course of intracellular edema and epileptiform activity following prenatal cerebral ischemia in sheep. Stroke 22:516-521

30. Shimell CJ, Fritz VU, Levien SL 1989 A comparative trial of flunarizine and propranolol in the prevention of migraine. S Afr Med J 77:75-77

31. Faber JJ, Thornburg KL 1983 Placental Physiology: Structure and Function of Fetomaternal Exchange. Raven Press, New York

32. Akaike N, Kostyuk PG, Osipchuck YV 1989 Dihydropyridine-sensitive low- 
threshold calcium channels in isolated rat hypothalamic neurons. J Physiol (Lond) 412:181-195

33. Wibo M, Delfosse 1, Godfraind T 1983 Action of flunarizine and cinnarizine on calcium fluxes in synaptosomal preparation from rat cerebral cortex. Arch Int Pharmacodyn Ther 263:333-334

34. Holler M, Dierking H, Dengler K. Tegtmeyer F, Peters T 1986 Effect of flunarizine on extracellular ion concentration in the rat brain under hypoxia and ischemia. In: Battistine N, Courbier R, Fiorani P, Plum F, Fieschi C (eds) Acute Brain Ischemia, Medical and Surgical Therapy. Raven Press, New York, pp 229-236

35. Stein D, Vannucci RC 1988 Calcium accumulation during the evolution of hypoxic-ischemic brain damage in the immature rat. J Cereb Blood Flow Metab 8:834-842

36. Epstein RP, Daly JW 1982 Release of norepinephrine and dopamine from the brain vesicular preparations: effects of calcium antagonists. Cell Mol Neurobiol 2:205-213

37. Maloteaux JM, Octave JN, Laterre EC 1988 Functional dihydropyridine binding site associated with slow calcium channel in rat cultured neurons. Neurosci Lett 87:168-172

38. Beck T, Nuglisch J. Sauer D, Bielenberg GW, Mennel HD, Rossberg C, Krieglstein J 1988 Effects of flunarizine on postischemic blood flow, energ metabolism and neuronal damage in the rat brain. Eur J Pharmacol 158 : $271-274$
39. Lou HC, Lassen NA, Friis-Hansen B 1979 Impaired autoregulation of cerebral blood flow in the distressed newborn infant. J Pediatr 94:118-121

40. Rich KM, Hollowell JP 1990 Flunarizine protects neurons from death after axotomy or NGF deprivation. Science 248:1419-1421

41. Johnson Jr EM, Koike T, Franklin J 1992 A "calcium set-point hypothesis" of neuronal dependence on neurotrophic factor. Exp Neurol 115:163-166

42. Cheng B, Mattson MP 1991 NGF and bFGF protect rat hippocampal and human cortical neurons against hypoglycemic damage by stabilizing calcium homeostasis. Neuron 7:1031-1041

43. Cheng B, Mattson MP 1992 IGF-I and IGF-II protect cultured hippocampal and septal neurons against calcium-mediated hypoglycemic damage. J Neurosci $12: 1558-1566$

44. Saad B, Constam DB, Ortmann R, Moos M. Fontana A, Schachner M 1991 Astrocyte-derived TGF-beta 2 and NGF differentially regulate neural recognition molecule expression by cultured astrocytes. J Cell Biol 115: 473-484

45. McNeil H, Williams C, Guan J, Dragunow M, Lawlor P, Sirimanne E, Nikolics K. Gluckman P 1994 Neuronal rescue therapy with transforming growth factor $\beta_{1}$ after brain injury. Neuroreport 5 (in press)

46. Jensen A, Klossek H 1992 Effects of flunarizine on fetal circulatory centralisation during acute asphyxia in sheep. Proceedings of the Society for the Study of Fetal Physiology, Asilomar, CA. May 1992, 17:D-10 